\title{
The effects of one botulinum toxin type A (BTX-A) injection after UPPP
}

Tae Yong Yang • Tae Young Jang

Published online: 1 April 2008

(C) Springer-Verlag 2008

\section{Erratum to: Eur Arch Otorhinolaryngol}

\section{DOI: 10.1007/s00405-008-0624-x}

After online publication of the above article, the author requested the insertion of the following acknowledgement:

Acknowledgment. This article was supported by In-Ha University Hospital.

The online version of the original article can be found under doi: 10.1007/s00405-008-0624-x.

T. Y. Yang $\cdot$ T. Y. Jang $(\bowtie)$

Department of Otolaryngology, Head and Neck Surgery,

College of Medicine, Inha University,

3-Ga Shinheung-dong, Jung-Gu,

Incheon 400-711, South Korea

e-mail: mansatong2@naver.com; jangty@inha.ac.kr 